\title{
PERFIL DOS PRETENDENTES A ADOÇÃO INTERNACIONAL NO ESTADO DO TOCANTINS: UMA BREVE CONTEXTUALIZAÇÃO
}

\author{
TANIA MARA ALVES BARBOSA
}




\section{PERFIL DOS PRETENDENTES A ADOÇÃO INTERNACIONAL NO ESTADO DO TOCANTINS: UMA BREVE CONTEXTUALIZAÇÃO}

Tania MaraAlves Barbosa ${ }^{1}$

\section{RESUM 0}

Este artigo é um recorte de uma monografia de especialização sobre a temática A adoção internacional no Estado do Tocantins: estrutura institucional e metodologia para habilitação à adoção internacional no período de 2005 a 2009. Tem por objetivo traçar a estrutura que permeia a adoção internacional no Brasil e apresentar o perfil dos pretendentes à adoção internacional no Estado do Tocantins no período de 2005 a 2009.

Palavras-chave: Adoção internacional . Serviço Social. Política Social.

\section{ABSTRACT}

This article is an excerpt from a monograph of specialization about Intercountry adoption in the State of Tocantins, institutional structure and methodology for enabling international adoption in the period 2005 to 2009. It aims to show the structure that permeates the international adoption in Brazil and to present the profile of applicants to international adoption in the State of Tocantins in the period 2005 to 2009.

Keywords: International Adoption. Social Work. Social Policy.

\section{INTR ODUÇÃ $O$}

Este artigo é uma abordagem parcial do trabalho de

$1 \quad$ Assistente Social no Tribunal de Justiça do Estado do Tocantins. Especialista em Serviço Social: direitos sociais e competências profissionais pela CEAD/UNB e Mestre em Sociologia pela Universi dade de Coimbra - Portugal. E-mail: tmabarbosa@gmai l.com 
conclusão do curso de especialização em Serviço Social Direitos Sociais e Competências Profissionais - ministrado pelo Centro de Ensino à Distância da Universidade de Brasília (CEAD-UNB); Conselho Federal de Serviço Social (CFESS); eAssociação Brasileira de Ensino e Pesqui sa do Serviço Social (ABEPSS), realizado no ano de 2010 em Palmas - Tocantins com o tema: A adoção internacional no Estado do Tocantins: estrutura institucional e metodologia para habilitação à adoção internacional no período de 2005 a 2009.

Pretende-se apresentar aqui um breve perfil dos pretendentes à adoção internacional no Estado do Tocantins e das crianças requeridas por estes, salientando que se tomou por base o fato de ter no Brasil uma Legislação específica que disciplina a forma como a adoção internacional deve ser viabilizada, e haver, ai nda, por parte da comuni dade e técnicos em geral, muita dúvida sobre a forma como ela ocorre e sobre os critérios utilizados nas habilitações de pretendentes à adoção internacional. Dessa forma, buscou-se traçar, rapidamente, a metodologia utilizada para realização da habilitação dos pretendentes à adoção internacional, eemespecial no Estado do Tocantins, apreciando a relação entre os pareceres emitidos pela equipe técnica e, em especial, pel o assistente social, real izando, para fundamentação, um breve percurso histórico para o melhor entendimento da questão. 


\section{INSTITUTO DA ADOÇÃO - UMA BREVE CONTEXTUALIZAÇÃO HISTÓRICA}

No Brasil, a adoção remonta de seu passado colonial, em que as crianças "abandonadas" eram, conforme o modelo europeu, destinadas à roda dos expostos, mecanismo utilizado para proteger o anonimato dos pais biológicos que entregavam seu filho em adoção.

Naquela altura, grande preocupação era atribuída à preservação do anonimato dos pais biológicos, entretanto à criança não eram garantidos sequer os direitos relativos à manutenção da vida.

Weber (2008), sobre esse assunto, cita Orlandi (1988) quando, nesse sentido, afirma que ao analisar a roda dos expostos por um período detreze anos constatou quedas oi to mil e oitenta e seis crianças que ali foram entregues, três mil quinhentas e quarenta e cinco destas não sobreviveram, ou seja, mais de quarenta por cento morreram

As primeiras leis brasileiras a se manifestarem acerca da adoção foram "as Ordenações Filipinas e a Lei de 22 de setembro de 1828" (CÁPUA, 2007, p.74). Contudo, foi no Código de menores, de 1917, que pela primeira vez, exigiu-se fosse regulada a adoção pelo Sistema de J ustiça. Dessa forma, já se consubstanciou grande arcabouço teórico na área, pois o instituto da adoção já era previsto no Código Civil de 1917 (FIGUEIREDO, 2008).

Todavia, apesar de sua prática ser real izada desde então, 
foi apenas com o fim da doutrina da situação irregular e com a Constituição Federal de 1988 que se inaugurou o nascimento da doutrina da proteção integral. A partir de então, o instituto da adoção passou a ter nova caracterização; deixou para trás o preconceito e os estigmas relacionados à questão, e a criança e o adolescente passaram a ser vistos como pessoas em desenvol vimento, sujeitos de direitos e com prioridade absoluta; colocados, portanto, como categoria central da questão da adoção, difundi ndo em relação a este instituto a mental idade de que a "busca é de uma família para a criança”, e não de uma “criança para a família” (FIGUEIREDO, 2008).

A esse respeito Tiburzio assinala:

Neste aspecto a Constituição Federal de 1988 deu à criança e ao adolescente, em consonância com a Convenção Internacional dos Direitos da Criança e do Adolescente, a caracterização de prioridade absoluta, garantindo-Ihe ampla proteção social e uma concepção voltada para a idéia central de que o que se deve levar em consideração é o bem-estar da criança, e que esta concepção dever prevalecer, inclusive, quando da col ocação da criança em uma família substituta: Temse que a finalidade da moderna adoção é oferecer um ambiente familiar favorável ao desenvolvimento de uma criança, que, por algum motivo, ficou privada da sua família biológica. O quese pretendecoma adoção é atender às reais necessi dades da criança, dando-Iheuma família(TIBURZIO, 2004, p. 24).

A prioridadeabsolutaaos direitos decriançaseadol escentes foi reconhecida mundialmente e, no Brasil, a Constituição 
Federal de 1988 (CF) veio ratificar essa dimensão. Enquanto Lei complementar, disciplinadora do art. 227 da CF, a Lé no 8.069, de 13 de julho de 1990, veio estender, explicitar e normatizar a forma como tais direitos seriam garantidos e reconhecidos, apresentando, assim, os direitos infanto-juvenis como direitos incontestes. A cerca dessa real idade Cápua (2007) assevera que:

A CF/88 deu abrangência explícita aos direitos das crianças e dos adol escentes, estabel ecendo regras sobre trabalho e profissionalização, capacidade eleitoral, assistência e seguridade social, programações de rádio e televisão, múnus públ ico de proteção integral edever do Estado, garantias democráticas processuais, incentivo à guarda, prevenção contra entorpecentes, defesa contra o abuso sexual, estímulo à adoção e à isonomia filial. Dessa forma, encampou definitivamente a política de proteção integral da infância e da adolescência no Brasil (CÁPUA, 2007, p. 35).

Nessa conjuntura a adoção no Brasil iniciou um processo de regulamentação, no que foi imediatamente seguido pela adoção internacional, pois procedimentos dessa natureza começaram a ser realizados de forma irregular configurando sequestro internacional e tráfico de menores, o que suscitou a urgência da normatização da situação:

Após denúncia do deputado francês Leon Schwarzemberg no Parlamento Europeu, em 13 de outubro de 1992, houve intensos debates sobre o tráfico internacional de crianças correlacionado com a adoção intemacional. O deputado relatou que, na Itália, entre 1988 e 1992, apenas mil de um total de 
quatro mil crianças brasileiras adbtadas irregul armente permaneciam vivas. Desde então, muitas denúncias foramfeitas, ea questão da adoção intemacional tornour se matéria urgente no Brasil, principalmente porque as estimativas do Governo Federal eram alarmantes, pois indicavam que, entre os anos de 1980 e 1990, 19.071 crianças haviam sido adotadas por famílias americanas e européias e sua situação, após a adoção, era simplesmente uma incógnita (J ESUS, 2003, p. 142 apud CÁPUA, 2007, p. 91).

\section{A ADOÇÃO INTERNACIONAL - INSTITUTO DE EXCEPCIONALIDADE OU PRÁTICA COTIDIANA?}

No âmbito da Legislação Brasileira, especialmente no Estatuto da Criança e do Adolescente (ECA), a adoção internacional se tornou legal, mas entendida como instituto de excepcional idade, situação que pode ser mais bem explicitada nos termos de Cápua:

A adoção de brasileiros por estrangeiros, residentes ou domiciliados fora do país, é expressamente permitida pelo Estatuto da Criança e do Adolescente, devendo ser elaconsiderada, ao mesmo tempo, como umaalternativa e como uma exceção, em face do art. 31 do referido diploma legal. É al ternativa como medi da que substitui a adoção nacional, se assim exige o interesse do menor, proporcionando-Ihe um ambiente familiar adequado, ainda que fora de seu País, e dando-lhe condições para que possa vir a exercer seus direitos (CÁPUA, 2007, p. 111).

Isso indica que somente depois de esgotadas as 
possibilidades de colocação da criança em família substituta brasileira é que haverá possibilidade de concretização da adoção intemacional, posto esta ser um instituto concedido a estrangeiros quando não houver, de forma al guma, pretendentes nacionais à adoção.

O ECA destacou também a necessidade de que o candidato à adoção intemacional se habil ite no seu domićli io, o que garante a prerrogativa de o Estado de origem dos adotantes estar de pleno acordo com a adoção pretendida.

Nesse sentido, Tiburzio (2004) reitera:

No entanto, o Estatuto da Criança e do Adolescente fixou critério diverso de aplicação das leis, no $\S 1^{\circ}$ do artigo 51: "0 candidato deverá comprovar, mediante documento expedido pela autoridade competente do respectivo domicilio, estar devidamente habilitado à adoção, consoante às leis do seu país, bem como apresentar estudo psicossocial elaborado por agência especializada e credenciada no país de origem" (TIBURZIO, 2004, p. 31, grifo nosso).

Nessa perspectiva, é a partir da apresentação dessa documentação do país de origem que o pretendente à adoção internacional irá se habilitar perante o país do adotado. Deverá, então, entregar toda a "papel ada" requerida à autoridade central do Brasil que, neste país, tem seu órgão máximo na Secretaria Especial de Direitos Humanos da Presidência da República, e 
vinte e sete autoridades centrais, constituindo-se uma em cada uni dade da Federação.

\subsection{A função social da autoridade central perante o Instituto da adoção}

Surgiu para dar efetividade aos direitos da criança e do adolescente previstos no Estatuto da Criança e do Adolescentee na Convenção de Haia, Legislações respectivamente criadas em 1990 eem 1999 (CGJ/TO).

A primeira, conhecida em todo Teritório Nacional como "ECA" veio para inaugurar um novo paradigma, o da proteção integral, em detrimento do paradigma de regulação que estava em vigor e se baseava na doutrina da situação irregular.

A segunda se originou de uma movimentação internacional, com o intuito de regularizar situações de adoções irregulares ou até de adoções legalizadas, mas que não possuíam respaldo dos países adotantes, vindo à baila várias situações em que brasileiros, depois de anos vivendo em outro país, serem expatriados para o seu país de "origem" (aquele do seu nascimento), desqualificando a adoção realizada pelos pais estrangeiros. Casos como o de Djavan e o de J. C. O. podem ser citados como exemplos dessa situação:

Para complicar ainda mais, a nova lei de imigração americana, de1997, diz quetodo estrangei ro quecomete um crime, após o cumprimento de sua pena, deve ser mandado de volta ao país de origem. Assim, todas as 
crianças brasileiras adotadas por americanos que não obtiveram a cidadania correm o risco de ser devolvidas ao País. Djavan não é o único caso. A ISTOÉ teve conhecimento de pelo menos outros três. Sob acusação depraticar abuso sexual, o jovem Reginal do daSil vafoi colocado dentro deumavião edespachado de Michigan para o Recife, em agosto do ano passado. Pelo mesmo motivo, J.C.O. foi devolvido de Oregon, também nos Estados Uni dos, eviveagora numa entidadeassistencial no interior paulista. Traumatizado, o rapaz passa por um tratamento psicológico e psiquiátrico. Um novo caso também teria sido descoberto recentemente em Ohio, mas as autoridades brasileiras não o confirmaram oficialmente (Revista Isto é, 1999).

Assim, a Convenção de Haia veio dar resolutividade a situações de conflito não só legal, mas também psicológico e social, haja vista que situações como a descrita acima causaram,para além dos impactos individuais e familiares das pessoas envolvidas, grande comoção na sociedade e descrédito nas instituições jurídicas e sociais em âmbito internacional.

Mas a Convenção sinalizou uma nova reestruturação internacional da Adoção, e criou em cada país uma estrutura formal para se responsabilizar pela regularização do Instituto naquele país:

1. Cada Estado Contratante designará uma Autoridade Central encarregada de dar cumprimento às obrigações impostas pela presente Convenção. 2. Um Estado federal, um Estado no qual vigoram diversos sistemas jurídicos ou um Estado com unidades territoriais autônomas poderá designar mais de uma Autoridade Central e especificar o âmbito territorial ou pessoal de 
suas funções. O Estado que fizer uso dessa faculdade designará a Autoridade Central à qual poderá ser dirigida toda a comunicação para sua transmissão à Autoridade Central competente dentro desse Estado (Capítuloll da Convenção de Haia).

A Convenção, então, disciplinou que deveria haver um responsável pelo comando único das ações e, ao mesmo tempo, garantiu a descentralização Administrativa, trazendo para os estados a partilha da responsabilidade por ações dessa natureza. Desse modo, Figueiredo afirma que:

[...] as comissões estaduais assumiram o papel de Autoridades Centrais (instituto previsto na Convenção, a qual facul ta a existência de mais de uma del as em países de regime federativo como o Brasil) no âmbito dos respectivos Estados federados, com todas as implicações daí decorrentes (FIGUEIREDO, 2003, p. 119).

Dessa forma, a Convenção estabel eceu que estes órgãos deveriam manter organização e padronização do seu fazer, cooperação entre si e principalmente serem fiéis ao princípio de agir sempre em prol do interesse superior da criança e com respeito a seus direitos fundamentais (Convenção de Haia).

Desse diapasão, o Decreto ํo 3.174 foi instituído em 16 de setembro de 1999 enquanto detal hamento e regulamentação das novas premissas apresentadas na Convenção. Neste Decreto ficaram claramente estabelecidas a competência da autoridade central federal (afirmando que no Brasil esta fosse de competência da Secretaria Especial dos Direitos Humanos 
(SEDH), Órgão vinculado ao Ministério daJ ustiça) ea existência das autoridades centrais nos estados, a serem exercidas pelas CEJ AS ou órgãos análogos. No caso da inexistência destes, o próprio òrgão Central assumiria estas ações do Estado.

Tal atitude possibilitou mais credibilidade aos órgãos do Judiciário, pois trouxe mais organização, cientificidade, possibilidade de reflexão acerca das atividades implementadas e responsabilização dos executores das ações.

Às Cejas foram designadas ações de orientação às Varas de Infância e J uventude (ou à Vara que acumulasse esta função) em assuntos relativos à adoção, e disciplinou o funcionamento central izado no Estado, levando às Varas de todas as Comarcas do Estado Federado a se remeterem ao seu órgão de orientação direto.

Assim as Cejas se tornaram órgãos de orientação e supervisão dentro do Estado e, por tal fato, responsáveis pelo encaminhamento de informações, estatísticas, acompanhamento processual, entre outros; cabendo-lhes a realização da padronização no Estado, conforme a designação da autoridade central federal.

No intuito de democratizar o assunto, garantir a implementação da Convenção de Haia e deser órgão consul tivo, avaliativo edeorientação, foi criado também, pelo Decreto acima mencionado, o Conselho das Autoridades Centrais Brasileiras, com reuniões ordinárias semestrais, o qual é composto por representantes do Órgão Federal que representa a autoridade central de todos os Órgãos Estaduais (CEJAS), do Ministério 
das Relações Exteriores e do Departamento de Polícia Federal.

\subsection{Comissão E stadual J udiciária no E stado do Tocantins - Funcionamento e metodologia de análise de processos de adoção internacional}

No Estado do Tocantins, a Comissão Estadual J udiciária de Adoção (CEJ A-TO) é parte da estrutura administrativa da Corregedoria-Geral da Justiça, órgão pertencente ao Poder Judiciário do Estado do Tocantins que é responsável pela orientação e fiscalização das ações realizadas no seu âmbito de atuação.

Foi criadaem24 demarço de1994, por meio daResolução $\mathrm{n}^{\circ} 003$, de 1994, "com a finalidade de contribuir para a garantia dos direitos à convivência familiar e comunitária de crianças e adolescentes do Estado do Tocantins" (CGJ/TO) e exercer a função específica de autoridade central no Estado, executando atividades ligadas à organização, orientação, acompanhamento, normatização, dentre outros, conforme designação da atribuição que lhe for conferida.

Dentre as suas funções, destaca-se o fato de possuir a finalidade de auxiliar os Juizados da Infância e Juventude; e as Varas Cíveis quando estes não tiverem sido criados, emassuntos concementes à adoção nacional e internacional, tomando-se o Estado um Órgão Central deOrientação sobre assuntos relativos à adoção nacional e internacional de crianças e adolescentes para todas as Comarcas do Estado do Tocantins.

Revista Esmat, Palmas, Ano 5, № 5, pag. 159 a 189 - jan/jun 2013

171 
Podem-se citar como suas principais atribuições:

a) Organizar, para uso de todas as comarcas do Estado, Cadastro Geral e Unificado de Crianças declaradas em situação irregular, que necessitem de colocação em lar substituto mediante adoção; b) Organizar Cadastro de Pretendentes á adoção, nacionais e estrangeiros, residentes no país, a fim de disponibilizá-lo às diversas comarcas do Estado; c) Organizar o cadastro de pretendentes estrangeiros residentes fora do país, expedindo laudo de habilitação para apresentação ao juízo da criança a ser colocada em lar substituo; d) Manter intercâmbio com órgãos e instituições especializadas internacionais, públicas ou privadas, estas últimas reconhecidas econtroladas pelo país onde foram criadas, a fim de estabelecer sistemas de controle e acompanhamento de estagio de convivência no exterior; e) Admitir a col aboração de entidades nacionais especializadas, públicas ou privadas, estas últimas reconhecidamente idôneas e recomendadas pelo juiz da infância e juventude da comarca em que tiverem sede; f) Realizar trabal ho de divulgação de projetos de adoção, visando estimular a colocação da criança em lar substituto, combatendo preconceitos existentes em relação às crianças adotadas. g) A poio aos Juízes do Estado relativo aos procedimentos de adoção nacional e internacional, orientar sobre o Banco Nacional de Adoções (cadastro nacional de adoções), instituído pelo Conselho Nacional de J ustiça, na Resolução n.. 54, de 29 de abril de 2008; h) A poi o aos J uízes eservidores do Estado nos sistemas do Cadastro Nacional de Adolescentes em Conflito com a Lei - CNACL e do Cadastro Nacional de Crianças Acolhidas - CNCA, instituídos, respectivamente, pelas Resoluções n 77 e 93/2009-CNJ (CGJ/TO, grifo nosso). 
Dentre essas atribuições, urge destacar as mais recentes instauradas com a criação do Banco Único deAdoção, por meio da Resolução no 54, de 29 de abril de 2008, as quais se referem à organização e cadastro das adoções do Estado do Tocantins (CG) /TO).

No Estado do Tocantins, como a Ceja faz parte da Corregedoria-Geral da Justiça, possui como membro nato e hierarquicamente superior, o desembargador corregedor-geral que juntamente com um defensor público e três juízes indicados respectivamente pela Defensoria Pública e pelo Tribunal Pleno do Tribunal de Justiça do Estado do Tocantins compõem a Ceja. A despeito de não fazer parte dessa Comissão, o Ministério Público atua juntamente com ela em todas as atividades com vistas à fiscalização e garantia dos direitos ali tratados. Esses membros, após aindi cação, devemser nomeados pelo presidente do Tribunal de Justiça via publicação no Diário da Justiça, veículo de circulação oficial e diária do Poder Judiciário do Estado do Tocantins (CGJ/TO, 2000).

Nessa configuração, a Ceja-TO disciplina, conforme a Legislação Federal, tanto a adoção nacional quanto a adoção internacional no âmbito do Estado. A adoção nacional éreal izada nas Comarcas e carece de inscrição prévia do pretendente no cadastro deadoção, quando deveapresentar toda a documentação necessária, em que estão presentes, além do requerimento, os documentos pessoais, documentos comprobatónios de moradia, renda e de saúde.

A avaliação, preparo prévio e acompanhamento desses 
adotantes são realizados pela equipe técnica do Juizado da Infância que, na Comarca de Palmas, capital do Estado do Tocantins, é composta por uma psicóloga efetiva e dois assistentes sociais (um efetivo e outro à disposição) os quais, para este fim, utilizam diversos procedimentos operacionais, tais como visitas domiciliares, entrevistas, testes (psicológicos), reuniões e outros.

Destarte, deve-se mencionar que as alterações efetivadas pela Lei ㄲo 12.010, de 3 de agosto de 2009, conhecida como "nova Lei da Adoção", vieram garantir que a excepcionalidade da adoção internacional seja real mente cumprida pelo reforço e estabel ecimento de requisitos como a prioridade da permanência da criança emsua família natural, estendendo o direito à família extensa e propondo inserção destas em programas de apoio e orientação, se for o caso; e o não reconhecimento das adoções real izadas sem processamento do judiciário.

Concernenteà adoção internacional, a Ceja-TO processa toda a ace itação do pedi do de habi litação à adoção internacional , que envolve análise do processo legal pela autoridadejudiciária e participação do Ministério Público e o encaminha para a análise da equi pe técnica (assistente social, psi cóloga e médica pedi atra), a qual emite pareceres favoráveis ou desfavoráveis ao requerimento do estrangeiro, conforme explicita Tiburzio,

A CEJA, além do estudo prévio das condições sociais e psicológicas e análise da estabilidade conjugal , ela é autoridade, idoneidade e seriedade no processamento 
das informações referentes aos interessados estrangeiros na adoção (2004, p. 43).

\subsection{Procedimentos para realização do requerimento da habilitação à adoção internacional}

Conforme consta do Regimento Intemo da CejaTO, para requerer a habilitação à adoção internacional, é necessário que o candidato à adoção internacional, pessoalmente, ou por intermédio de seu representante legal ou de entidade credenciada, faça um requerimento à Ceja-TO, o qual deverá estar acompanhado de documentos emitidos no seu país de origem e comprovem que o requerente está habilitado para adotar no seu país de origem; e realize estudo biopsicossocial com apresentação do laudo, apresentação da Lei que rege a adoção no país de origeme a comprovação de sua vigência.

Deverá, ainda, apresentar duas declarações, uma escrita à mão, afirmando saber que no Brasil a adoção é gratuita e irrevogável. Na outra, deverá se comprometer a não estabelecer contato com parentes ou detentores da guarda do adotando antes que o resultado do requerimento seja expedido pela Ceja-TO, antes quetodas as possi bil idades deadoção nacional tenhamsido esgotadas, e finalmente até que a criança seja disponibilizada para adoção internacional pela autoridade judiciária. Os requerentes deverão apresentar cópia do passaporte, documento de identidade de estrangei ros em território nacional.

O Regimento Interno da CejaTO é contundente em

Revista Esmat, Palmas, Ano 5, № 5, pag. 159 a 189 - jan/jun 2013 
afirmar que todo o documento que constar do processo de adoção internacional quevier grafado emidioma diferenteao da Língua Portuguesa do Brasil deverá ser traduzido por profissional juramentado no Brasil e ainda ser autenticado no Consulado brasileiro presente no país de origem dos requerentes.

Ademais, o estudo social, psicológico, o atestado de sanidade física e mental, o atestado de antecedentes criminais, o atestado de residência, a declaração de rendimentos e a certidão sobre o estado civil dos pretendentes devem ter todas as informações que conteria documento análogo realizado no Brasil. A partir do protocolo na Ceja-TO, do requerimento com toda a documentação anexa, será realizada a autuação dos autos ea anál ise processual do requerimento.

\section{METODOLOGIA QUE FUNDAMENTOU A REALIZAÇÃO DESTE TRABALHO}

Os dados presentes neste artigo foram retirados da pesquisa executada com o fim de elaboração de Trabalho de Conclusão do Curso de Especial ização realizado pela UNB em parceria com a ABEPSS. A descrição da metodologia, de forma simplificada, pode ser relatada nos seguintes termos:

Considerou-se, para realização da pesquisa bibliográfica, o acervo bibliográfico de propriedade da pesquisadora e da Biblioteca do Centro Universitário da Universi dade Luterana do Brasil e da Biblioteca do Tribunal de J ustiça, em Palmas.

Foi tambémreal izado levantamentonaComissãoEstadual

Revista Esmat, Pal mas, Ano 5, no 5, pag. 159 a 189 - jan/jun 2013 
Judiciária deAdoção do Estado do Tocantins (CEJA-TO) sobre a estrutura institucional responsável pelos procedimentos de adoção internacional no Tocantins e sobre a metodologia utilizada pela Ceja-TO para habilitação dos pretendentes à adoção internacional.

A intemet foi considerada como base de dados para pesquisa de artigos, monografias, dissertações, teses, revistas, jornais, legislações e livros.

No tocante à pesquisa de campo, procedeurse à análise dos processos de adoção internacional autuados nos últimos cinco anos, com vistas à identificação da nacionalidade dos adotantes, faixa etária, estado civil dos pretendentes à adoção. Quanto às crianças adotadas, faixa etária-raça; e número de processos com habilitação deferida eindeferidas.

\subsection{Descrição da coleta dos dados}

Real izou-se leitura e coleta de dados durante sete dias úteis, com a colaboração da Ceja-TO em todas as etapas; nos documentos se procedeu à busca por informações sobre os pretendentes à habilitação para adoção e ao "tipo" de criança requerida, a fim de construir um perfil simplificado do candidato à habil itação à adoção internacional no Estado do Tocantins. 


\section{APRE SE NTAÇÃO E DISC USSÃO DOS RE SULTADOS}

\subsection{Perfil dos requerentes à habilitação a adoção internacional e das crianças a serem adotadas}

Foram analisados todos os processos de requerimento à adoção internacional no período de 2005 a 2009, num total de oito processos. Percebeurse, apesar do número pequeno de processos concluídos no período, ter este sido suficiente para se explicitar a forma deoperacional ização dos feitos eas principais características dos requerentes.

No tocante à nacionalidade dos adotantes, pôde-se observar ter havido requerimento de pretendentes suecos, franceses, portugueses e alemães, com predominância de requerentes franceses e suecos.

Percebeurse, nos processos analisados, que todos os requerentes são heterossexuais e casados. Dessa forma, o requerimento à habilitação foi feito em conjunto.

No tocante à situação financeira, pode-se afirmar, por meio das fotos e descrição de situação de vida, que os casais requerentes possuemrendacaracterísticadepadrão classemédiaalta, não podendo aqui seestabel ecer um parâmetro comparativo formal entre eles, pois haveria de se fazer a conversão das moedas de todos os países para um único método conversor.

No que concerne ao tempo de casamento, os requerentes apresentam uma média de sete vírgula três anos de casados, entretanto se pode afirmar que a maioria deles já possuíam união 
estável. Esta média seria ainda mais al ta caso se considerasse a união estável como um dado a ser analisado.

Em relação à faixa etária, a idade mínima entre todos os requerentes foi de trinta e cinco anos; e a idade máxima, de cinquenta e três anos. Para se estabel ecer um parâmetro de comparação, foi realizada a soma aritmética das idades por sexo, e dividida pelo número de autos processuais, chegando à conclusão de que a média de idade dos requerentes (homens e mulheres) está entre quarenta ecinquenta anos.

Nosautos, constamai ndacaracterísticasindividuais, como a raça de cada requerente, bem como fotografias e depoimentos de amigos e parentes, numa tentativa de aproximação do manuseador dos autos em relação à realidade vivenciada por aqueles. Perceptível, pois, a importância da aceitação social, tanto no país de origem como no de adoção, pelo casal, para o processo ser viabilizado.

No tocante à raça, noventa e três vírgula setenta e cinco por cento dos casais requerentes se autointitularam como pertencentes àraça branca, sendo queapenas uma pessoa do sexo feminino (seis vírgula vinte e cinco por cento) se autointitulou "morena":

Com relação ao perfil da criança, podem ser destacadas características específicas citadas pelos requerentes, como raça, idade e condições de saúde desejada. Assim, no que se refere à raça da criança, apesar de mais de noventa por cento dos requerentes se considerarem de raça branca, não houve objeção clara acerca de filhos de outra raça, posto haver indicação de 
aceitação de crianças negras ou mestiças por setenta e cinco por cento dos pretendentes. Apenas vinte e cinco por cento dos requerentes optaram, exclusivamente, por crianças de raça branca.

Essa situação pode indicar uma superação da ideia da criança enquanto objeto de satisfação individual dos adultos e também apontar a raça enquanto característica individual, que não pode ser sobreposta aos demais vínculos nem sequer ser entendida como mecanismo de exclusão.

Em relação ao sexo da criança desejada, a maior parte dos requerentes não fez distinção; aceitou tanto meni nas quanto meni nos, mas trinta e sete vírgula cinco por cento ainda desejam meninas, situação muito semelhante à dos adotantes nacionais do Brasil (MOREIRA, 2010).

Inquiridos sobre a aceitação de grupo de irmãos, sessenta e dois vírgula cinco por cento dos requerentes indicaram a aceitação de até duas crianças, os demais (trinta e sete vírgula cinco por cento) não mencionaram explicitamente a não aceitação, tampouco sua posição a respeito da situação.

Nesse contexto, pôde-se perceber o desejo, por parte de cinquenta por cento dos requerentes, de adoção de apenas uma uma criança. Os demais requerentes expressaram a aceitação de mais uma criança.

Também em relação à faixa etária das crianças pôdese perceber grande similaridade à preferência dos adotantes 
nacionais². Sobre essa situação, uma pesquisa real izada pelo Conselho Nacional de Justiça (CNJ) afirma que:

[...] há 4.840 crianças para serem adotadas e 27.342 pessoas habilitadas para adotar no País. O número é atualizado diariamente $\mathrm{O}$ que não muda é que sobram nosabrigosascriançasquenãoatendemàscaracterísticas preferidas por quem adota no Brasil: recém-nascidos, brancos, do sexo feminino (MOREIRA, 2010).

Ressaltarse, nesse aspecto, não ter havido, nos processos de adoção internacional anal isados, requerimento da adoção de crianças mai ores de sete anos; aliás, a preferência se deu por crianças de zero a três anos de idade (setenta e cinco por cento).

\subsection{Situação final dos Processos}

No decorrer da anál ise dos autos de habil litação à adoção internacional, foi possível verificar que no período de 2005 a 2009 foram autuados oito requerimentos de habi litação à adoção internacional, tendo como resultado final o deferimento de trinta e sete vírgula cinco por cento dos autos:

De cem por cento dos processos autuados no período de 2005 a 2009, sessenta e dois vírgula cinco por cento dos autos foram indeferidos e arquivados.

Estabelecendo relação entre pareceres sociais favoráveis

$2 \quad$ A respeito deste assunto, Vieira (2003) ao realizar pesquisa junto a cadastros de candidatos a pais adotivos que procuraram o Grupo de Apoio à Adoção de Rio Claro / SP percebeu que "quanto menor for a criança, maior é a probabilidade de ela ser adotada" e ainda foi notado claramente que "ninguém se mostrou disposto a adotar uma criança acima de 7 anos". Pode-se afirmar que esta é uma situação que se repete pelo Brasil afora. 
e processos indeferidos e arquivados, foi possíved notar que, no universo dos processos indeferidos e arquivados, os pareceres social e psicológico favoráveis al cançaram sessenta por cento; os demais pareceres, quarenta por cento ou não foram proferidos ou foramnegados.

Os dados expostos, poderiam trazer a ideia ingênua de que a emissão do parecer social seria irrelevante para o processamento das adoções internacionais, pois, mesmo a mai oria dos pareceres sociais sendo favoráveis, isso não foi óbice para o indeferimento e arquivamento de sessenta e dois vírgula cinco por cento dos autos.

Entretanto, fazendo uso de um ol har mais técnico, numa análise qualitativa dos dados, pôde-se perceber ser descabida esta ideia, pois, ao verificar os motivos dos indeferimentos e arquivamentos dos processos em questão, observa-se que, independentemente da emissão do parecer do assistente social, os autos obteriam o mesmo fim, uma vez que as justificativas para o indeferimento e arquivamento dos processos não dizem respeito a motivos queinval idem ou neguema qual idade técnica dos pareceres, mas se referem a prazos extrapolados (perda da val idadedo documento deadoção do país deorigem), ausênciade respostados requerentesà sol icitação daCeja-TO dedocumentos adicionais, ausência de real ização de tradução juramentada do idioma do país de origem para o idioma português e ausência de pareceres técnicos do país de origem.

Contudo, se a relação entre emissão de pareceres favoráveis e indeferimento e arquivamento dos autos não pode 
ser um dado considerado como suficiente para desqualificar o parecer social, um dado que se toma importante é o da relação positiva entre deferimento de habilitação e parecer social favorável, que neste caso específico, foi de cem por cento. Assim, há um resul tado coincidente entre o total dos processos em que a habilitação foi deferida e sua condição de conter o parecer técnico do assistente social favorável. Importante se faz destacar que a análise técnica pode ou não ser levada em consideração pel a autoridade judiciária.

Concementeà rel ação entreo parecer do assistente social e o parecer psicológico, foi possível verificar que em cem por cento dos processos remetidos às duas categorias os pareceres tiveram resultados coincidentes

\section{CONSIDERAÇÕES FINAIS}

No tocante à adoção internacional propriamente dita, verificou-se que, a despeito da adoção internacional ser um instituto de excepcionalidade, atualmente existe uma estrutura consol idada para adoção internacional no Brasil, com descentralização das ações, dividida entre a Secretaria Especial dos Direitos Humanos (SEDH) e as Comissões Estaduais Judiciárias Estaduais (CEJ AS).

A respeito do funcionamento desses órgãos ainda há muito que conhecer, mas, conforme esta pesquisa se propôs, percebeu-se haver coerência entre a estrutura governamental federal e estadual para consecução dos procedimentos, todos 
regidos por legislação nacional e internacional.

Nesse sentido, a CejaTO realiza seus trabal hos com responsabilidade e competência técnica. Todavia, pode ampliar seu leque deatuação; eparaisso, sugere-sea manutenção deuma equi peinterdiscipl inar na sua secretaria, que poderá assessorála em todas as atribuições que lhe são pertinentes, propondo novas alternativas de ação.

No que conceme à responsabilidade de o Estado Nacional por prover às suas crianças, garantindo-lhes distribuição de renda, educação, saúde, habitação, entre outros, nota-se, mais uma vez, a falência do Estado Nacional no respeito emanutenção da cidadania nacional, eapresenta-se, explicitamente, afacedo estado capital ista, que se utiliza da estratégia de "global izar" o problema gerado pelo capital, propiciando solução focada na situação individual de cada criança abandonada - a adoção internacional -, conseguindo, ademais, na esteira da situação, estreitar suas relações internacionais com acordos, negociações, comércio etc.

Nessa esfera, o desenvolvimento econômico aparece, ainda, como primordial, evem, no Brasil , apresentando-secomo estrutura desucesso, a despeito de queo social, cultural ea posse dos bens e serviços não sejam apropriados pela maior parte da população brasileira. Quanto às crianças que são adotadas por estrangeiros, estas são alijadas dos seus direitos ante o Estado Brasileiro.

Emrel ação à equi petécnica e, especial mente, ao assistente social, pode-se afirmar que hoje a prática de atuação desse profissional nos autos de habilitação à adoção internacional já se 
consolidou, e os limites postos aos profissionais que atuam nessa área ai nda são muitos, haja vista se encontrarem diante de uma cul turadi ferente, padrão social comunitárioe, também, econômico diverso da real idadenaqual estão inseridos. Porémnão hádúvidas de que o reconhecimento da necessidade da avaliação social já se traduz no reconhecimento da importância de se garantir que a criança e o adolescente tenham todos os seus direitos garantidos.

Percebeurse que tanto a adoção quanto a adoção internacional não constituem respostas à problemática instal ada para crianças e adolescentes que permanecem nos abrigos. Esta é uma das expressões da questão social que está posta e que necessita derespostas, às quais, via de regra, têmsido oferecidas por políticas sociais, nestecaso, a adoção.

\section{REFERÊNCIAS BIBLIOGRÁFICAS}

BEHRING, E.R.; ALMEIDA, M. H. Tenório. Trabalho e Seguridade Social: o neoconservadorismo nas políticas sociais. In: BEHRING, E.R.; ALMEIDA, M.H. T. de (orgs.). Trabalho e seguridade social: percursos e dilemas. São Paulo: Cortez, 2008.

BEHRING, E.R.; C ontra-R eforma: desestruturação do Estado e perda dos direitos. São Paul o: Cortez, 2003. 
. Política Social no capitalismo tardio. São Paulo: Cortez, 2007.

BRASIL. Presidência da República. Decreto № 3.174/99. Designa as Autoridades Centrais encarregadas de dar cumprimento às obrigações impostas pela Convenção Relativa à Proteção das Crianças e à Cooperação em Matéria de Adoção Internacional, institui o Programa Nacional de Cooperação em Adoção Internacional e cria o Conselho das Autoridades Centrais Administrativas Brasileiras. Brasília-DF. Disponível em: বhttp://www.planalto.gov.br/ccivil_03/decreto/d3174. htm〉. Acesso em: 24 maio 2010.

BARROCO, MariaLúcia Silva. Fundamentos Éticos do Serviço Social. In: CFESS/ABEPSS (Org.). Serviço Social: Direitos Sociais e Competências Profissionais. Brasília: CEAD-UNB, 2009.

BRASI L. PresidênciadaRepública. Lei nำ12.010, de03deagosto de 2009. Dispõe sobre adoção; altera as Leis nos 8.069 , de 13 de julho de 1990 - Estatuto da Criança e do Adolescente, 8.560, de 29 de dezembro de 1992; revoga dispositivos da Lei no 10.406, de 10 de janeiro de 2002 - Código Civil, e da Consolidação das Leis do Trabal ho - CLT, aprovada pelo Decreto-Lei no 5.452, de 1 o de maio de 1943; e dá outras providências. Disponível em: বhttp://www.planalto.gov.br/ccivil_03/_Ato2007-2010/2009/ Lei/L12010.htm> A Acesso em: 10 set. 2010. 
BRASIL. Presidência da República. Lei no. 8069, de 13 dejulho de 1990. Dispõe sobre o Estatuto da Criança e do Adolescente e dá outras providências. Brasília-DF. Disponível em: 〈http:// www.planalto.gov.br/ccivil_03/Leis/L8069.htm>. Acesso em. 21 jan. 2010.

CÁPUA, Valdeci Ataíde. Critérios para obtenção da adoção internacional nos feitos da Comissão E stadual J udiciária de A doção do E stado do E spírito Santo - Brasil. Dissertação de Mestrado da Facul dade de Direito de Campos. Mestrado em Direito. Disponível em: «tttp://www.fdc.br/Arquivos/Mestrado/ Dissertacoes/IntegraNaldeciAtaideCapua.pdf $>$. Acesso em: 30 abr. 2010.

CGJ/TO - Corregedoria-Geral da Justiça do Estado do Tocantins. Comissão Estadual J udiciária de adoção do Estado do Tocantins. Sobre a CEJ A. Disponível ems 〈http://www.tjto.jus. br/corregedoria/corregedoria/ceja.aspx\#tapresentação>. Acesso em: 06 jun. 2010.

CGJ/TO - CorregedoriaGeral da Justiça do Estado do Tocantins. Regimento Interno da Comissão Estadual J udiciária de adoção do Estado do Tocantins- CEJ A/TO. 30 de março de 2000. Disponível em: বhttp://www.jto.jus.br/corregedoria/ corregedoria/ceja/REGIMENTO\%20INTERNO\%20DA\%20 CEJA.pdf >. Acesso em: 07 jun. 2010. 
CONSELHO FEDERAL DE SERVIÇO SOCIAL-CFESS (org.). 0 estudo social em perícias, laudos e pareceres técnicos: contribui ção ao debate no Judiciário, Penitenciário e na Previdência Social. São Paulo: Cortez, 2003.

CONSELHO NACIONAL DE JUSTIÇA. Resolução n. 54, de 29 de abril de 2008. Dispõe sobre a implantação e funcionamento do Cadastro Nacional deAdoção. Disponível em < http://www. cnj.jus.br/index.php?option=com_content\& view=article\&id=3 976:resolu-no-54-de-29-de-abril-de-2008\&catid=57:resolucoes \&ltemid=1085>. Acesso em: 10 set. 2010.

CONVENÇÃO DE HAIA. Disponível em: 〈http://www. planal to.gov.br/ccivil_03/decreto/d3087.htm>. Acesso em 24 maio 2010.

COUTINHO, C.N. Contra a corrente: ensaios sobre a democracia e o socialismo. São Paulo: Cortez, 2000.

FALEIROS, Vicente de Paula. A política social do Estado C apitalista. São Paulo: Cortez, 2000.

FÁVERO, Eunice. Instruções Sociais de Processos, sentenças e decisões. In: CFESS/ABEPSS (Org.). Serviço Social: Direitos Sociais e Competências Profissionais. Brasília: CEAD-UNB, 2009. 
FIGUEIREDO, Luiz Carlos de Barros. A doção Internacional: Doutrina e prática. Juruá Editora:Curitiba, 2003.

FONSECA, Claudia. Da circulação de crianças à adoção internacional: questões de pertencimento e posse. Disponível ems 〈http://www.scielo.br/pdf/\%0D/cpa/n26/30384.pdf>. Acesso ems 02 maio 2010.

GIL, Antonio Carlos. Como elaborar Projetos de Pesquisa. São Paulo: EditoraAtlas: 1996.

GUERRA, Yolanda. A instrumentalidade no Trabalho do Assistente Social. Publicado em 2004 e revisto em 2007. Disponível em: <http://www.danielafonso.com.br/files/ Yolanda\%20Guerra.pdf $>$. Acesso em: 05 abr. 2010.

A dimensão Investigativa no exercício profissional. In: CFESS/ABEPSS (Org.). Serviço Social: Direitos Sociais e Competências Profissionais. Brasília: CEAD-UNB, 2009. IPEA/CONANDA. O Direito à Convivência Familiar e Comunitária: os abrigos para crianças e adolescentes no Brasil. 2004. Disponível em: <http://www.ipea.gov.br/005/00502001. jsp?ttCD_CHAVE=245>. Acesso em: 16 maio 2010. 